\title{
Teor foliar de nutrientes em Plantas daninhas e de Café Cultivadas em Competição ${ }^{1}$
}

\author{
Leaf Nutrient Content in Coffee Plants and Weeds Cultivated in Competition
}

FIALHO, C.M.T. ${ }^{2}$, SILVA, A.A. ${ }^{3}$, FARIA, A.T. ${ }^{4}$, TORRES, L.G. ${ }^{5}$, ROCHA, P.R.R. ${ }^{6}$ e SANTOS, J.B. ${ }^{7}$

\begin{abstract}
RESUMO - Neste trabalho avaliou-se o acúmulo de nutrientes em plantas jovens de café e em plantas daninhas cultivadas em competição com a cultura. Mudas de café arábica cultivar Mundo Novo no estádio de quatro a cinco pares de folhas completamente expandidas foram transplantadas para vasos contendo $25 \mathrm{dm}^{3}$ de substrato. Utilizou-se o delineamento de blocos casualizados em esquema fatorial $(4 \mathrm{x} 4)$, com quatro repetições. Os tratamentos foram compostos por quatro espécies de plantas daninhas: Digitaria horizontalis, Brachiaria decumbens, Brachiaria plantaginea e Mucuna aterrima, em quatro densidades de infestação (zero, duas, quatro e seis plantas por vaso), em convivência por 90 dias com uma planta de café. Para determinação dos teores foliares dos nutrientes das plantas de café e das plantas daninhas, realizou-se coleta de folhas na parte mediana das plantas de café e das plantas daninhas. Todas as espécies de plantas daninhas, quando em convivência com o café, proporcionaram menor teor de nutrientes nas folhas da cultura, principalmente com o incremento da densidade de plantas, exceto para as concentrações de $\mathrm{N}$ nas folhas do cafeeiro que conviveram com $M$. aterrima. Os teores de nutrientes nas folhas das plantas daninhas diferiram por espécie, indicando capacidade diferenciada de ciclagem de nutrientes. As espécies daninhas destacaram-se com maior teor foliar de alguns nutrientes, sendo $D$. horizontalis em $\mathrm{P}$ e Fe, B. plantaginea em $\mathrm{P}, \mathrm{Mg}$, Mn e $\mathrm{Zn}$ e $M$. aterrima em $\mathrm{N}$, Ca e $\mathrm{Zn}$, independentemente da densidade de infestação.
\end{abstract}

Palavras-chave: Coffea arabica, competição, nutrição mineral, Mucuna aterrima.

\begin{abstract}
This work aimed to evaluate nutrient accumulation in young coffee plants and weeds cultivated in competition during 90 days. Mundo Novo coffee seedlings at the stage of four to five pairs of fully-expanded leaves were transplanted into pots with $25 \mathrm{dm}^{-3}$ of substrate. The experiment was arranged in a randomized block design, in a factorial scheme (4x 4), with four replications. The treatments were constituted of four weed species: Digitaria horizontalis, Brachiaria decumbens, Brachiaria plantaginea, and Mucuna aterrina, at four infestation densities (zero, two, four, and six plants per pot), in coexistence with one coffee plant, during 90 days. To determine the foliar nutrient content, leaves were collected from the median part of the coffee plants and of the weeds. When in coexistence with the coffee plants, all the weeds provided a lower nutrient content in the leaves of the culture, mainly with increased plant density, except for the $N$ concentration in the leaves of the coffee plants that coexisted with $\boldsymbol{M}$. aterrina. The nutrient contents in the leaves of the weeds differed according to the species, indicating differentiated capacity of nutrient recycling. The weeds presented higher content of some nutrients, as follows: D. horizontalis in $\mathrm{P}$ and $\mathrm{Fe}$; B. plantaginea in $\mathrm{P}, \mathrm{Mg}, \mathrm{Mn}, \mathrm{Zn}$ and $\mathbf{M}$. aterrina in $\mathrm{N}$, Ca and $\mathrm{Zn}$, regardless of infestation density.
\end{abstract}

Keywords: Coffea arabica, competition, mineral nutrition, Mucuna aterrima.

1 Recebido para publicação em 15.3.2011 e aprovado em 28.9.2011.

2 Eng.a.-Agra ${ }^{-}$, M.Sc., Doutoranda do Dep. de Fitotecnia, Universidade Federal de Viçosa - DFT/UFV, 36570-000 Viçosa-MG, <cintiamtfialho@yahoo.com.br>; ${ }^{3}$ Eng ${ }^{\circ}$.-Agr ${ }^{\circ}$., D.Sc., Professor Associado, DFT/UFV, <aasilva@ufv.br>; ${ }^{4}$ Acadêmico do curso de Agronomia, UFV, < autieresteixeira@yahoo.com.br>; ${ }^{5}$ Acadêmica do curso de Agronomia, UFV, <liviagtorres@gmail.com>; ${ }^{6}$ EngoAgr ${ }^{\circ}$., M.Sc., Doutorando do Dep. de Fitotecnia, DFT/UFV, <pauloagro01@yahoo.com.br>; ${ }^{7}$ Eng $\stackrel{0}{\text {. }}$-Agr ${ }^{\circ}$., D.Sc., Professor, Universidade Federal dos Vales do Jequitinhonha e Mucuri - UFVJM, Faculdade de Ciências Agrárias, Campus II - Rodovia MGT 367 - Km 583, no 5000 Bairro Alto da Jacuba 39100-000 Diamantina-MG, <jbarbosasantos@yahoo.com.br>.

Planta Daninha, Viçosa-MG, v. 30, n. 1, p. 65-73, 2012 


\section{INTRODUÇÃO}

A competição entre plantas daninhas e culturas por recursos do meio (água, luz e nutrientes) é frequentemente relatada como causa direta da redução de produtividade das culturas, embora a limitação desses recursos possua efeitos distintos entre as espécies (Pitelli, 1985). Entre as diversas culturas perenes, o café destaca-se pela alta sensibilidade à competição exercida pelas plantas daninhas, com reflexos negativos no crescimento das plantas jovens. Essa alta sensibilidade da cultura do café à interferência das plantas daninhas pode ser atribuída à competição por nutrientes (Ronchi et al., 2003), luz e água (Alfonsi et al., 2005).

No período do transplantio das mudas para o campo, até o segundo ano pós-transplantio, as plantas de café apresentam crescimento lento e deixam o solo exposto à luz. Dessa forma, a infestação e o crescimento das plantas daninhas são favorecidos, e o crescimento do cafeeiro é, consequentemente, prejudicado caso o controle não seja efetuado em tempo hábil, sobretudo na linha de plantio do cafeeiro (Ronchi et al., 2003, 2007).

Entre os fatores passiveis de competição pelas plantas, destacam-se os nutrientes, os quais podem ser afetados por vários fatores, como o teor de água no solo, por aspectos específicos dos competidores e também pelas diferenças no hábito de crescimento e requerimento de nutrientes pelas espécies envolvidas. Algumas espécies de plantas daninhas são mais competitivas com as culturas, devido à sua maior eficiência na absorção e utilização de nutrientes (Di Tomaso, 1995). Por exemplo, plantas de Bidens pilosa, em densidade equivalente a 75 plantas por $\mathrm{m}^{2}$, extraem e acumulam mais de nove, quinze, sete e oito vezes a quantidade de $\mathrm{N}, \mathrm{P}, \mathrm{K}$ e $\mathrm{S}$, respectivamente, comparada ao cafeeiro (Ronchi et al., 2003).

A capacidade de competição das plantas daninhas pode ser medida pelo seu potencial de redução na produtividade das culturas, cujo controle, nas últimas décadas, foi realizado com aplicação de herbicida, como medida eficiente e econômica para diminuir sua incidência e proliferação. Todavia, existem evidências de que o controle total das plantas daninhas, durante todo o ciclo das culturas perenes, tem reduzido a sustentabilidade desses cultivos. Algumas pesquisas têm comprovado a eficiência na adoção de sistemas integrados de manejo de plantas daninhas com base em cultivos consorciados. Nestes, espécies cultivadas junto com a cultura principal, em diferentes densidades, são capazes de suprimir a interferência de plantas daninhas na entrelinha da cultura (Baumann et al., 2001). Há relatos da experiência bem sucedida do uso de faixas de controle de plantas daninhas, como Brachiaria decumbens (Souza et al., 2006) e adubo verde (Paulo et al., 2001), entre outras espécies, em consórcio com o café. Portanto, evidencia-se a necessidade de pesquisas sobre competição das espécies daninhas com a cultura do café, em que conceitos integrados dos mecanismos de competição precisam ser analisados (Mortensen et al., 2000). Nesse sentido, novas estratégias devem estar focadas na biologia dessas espécies e na sua interação com as culturas.

Objetivou-se, neste trabalho, avaliar o acúmulo de nutrientes em plantas jovens de café arábica e em espécies de plantas daninhas, cultivadas em convivência e em diferentes densidades de infestação das plantas daninhas, visando subsídios para o desenvolvimento do manejo das plantas em lavouras de café.

\section{MATERIAL E MÉTODOS}

O experimento foi realizado sob condições de casa de vegetação. Mudas de café cultivar Mundo Novo (linhagem 374/19) produzidas por semeadura direta em sacolas de polietileno, no estádio de cinco pares de folhas completamente expandidas, foram transplantadas para vasos contendo $25 \mathrm{dm}^{3}$ de substrato, composto por solo peneirado e esterco de curral curtido (3:1). Para elevar a saturação por bases do solo (substrato) para 60\%, utilizou-se superfosfato simples (100 g por vaso) e calcário dolomítico (PRNT=80\%) (8,5 g por vaso). Além disso, aos 30 e 60 dias após o transplantio das mudas, realizou-se adubação das plantas, aplicando-se, em cobertura, cloreto de potássio (31,8 g por vaso) e ureia (10 g por vaso), tomando-se como base os resultados das análises física e química. O solo utilizado foi Latossolo Vermelho-Amarelo, cujas características 
físicas foram: classe textural: argiloarenosa; análise granulométrica em dag $\mathrm{kg}^{-1}$; areia, 46, silte, 5 , e argila, 49. As características químicas foram: $\mathrm{pH}$ água: 4,7; $\mathrm{P}: 2,3 \mathrm{mg} \mathrm{dm}^{-3}$; $\mathrm{K}$ : $48 \mathrm{mg} \mathrm{dm}^{-3} ; \mathrm{Al}^{+3}: 0,6 \mathrm{cmol}_{\mathrm{c}} \mathrm{dm}^{-3} ; \mathrm{H}+\mathrm{Al}$ : $6,27 \mathrm{cmol}_{\mathrm{c}} \mathrm{dm}^{-3} ; \mathrm{Ca}^{+2}: 1,4 \mathrm{cmol}_{\mathrm{c}} \mathrm{dm}^{-3} ; \mathrm{Mg}^{+2}$ : 0,4 $\mathrm{cmol}_{\mathrm{c}} \mathrm{dm}^{-3}$; SB: $1,92 \mathrm{cmol}_{\mathrm{c}} \mathrm{dm}^{-3}, \mathrm{t}: 2,52$; T: 8,19; P-rem: 24,3 $\mathrm{mg} \mathrm{L}^{-1}$; V: 23,00\%; m: 24\%; e MO: 2,4 dag $\mathrm{kg}^{1}$.

O experimento foi instalado em blocos casualizados, com quatro repetições, no esquema fatorial (4 x 4), com quatro espécies de plantas daninhas (Brachiaria decumbens, Digitaria horizontalis, Brachiaria plantaginea e Mucuna aterrima) e quatro densidades (zero, duas, quatro e seis plantas por vaso). A parcela experimental foi constituída de um vaso, contendo uma planta de café.

Após 60 dias de cultivo do café, em setembro de 2008, realizou-se o plantio ou transplantio das espécies de plantas daninhas no vaso. Sementes de D. horizontalis, B. decumbens e $B$. plantaginea foram semeadas em bandeja de plástico, utilizando-se como substrato areia lavada. Quando as plântulas se apresentavam com duas folhas expandidas, foram transplantadas para os vasos de café. Contudo, para a espécie $M$. aterrima, realizou-se a semeadura diretamente nos vasos. O período de convivência no mesmo vaso, entre a planta de café e as plantas daninhas, foi aquele compreendido entre a emergência ou transplantio (0 DAT) destas e a colheita do experimento, que foi realizada no início do florescimento das espécies gramineas, aos 90 DAT.

Para determinação dos teores de macro e micronutrientes, dos tecidos foliares das plantas, foram coletados o terceiro e quarto pares de folhas de ramos plagiotrópicos, situados no terço médio das plantas de café; para as espécies daninhas, coletou-se uma amostra de folhas (terceira folha a partir do ápice das plantas), no início do florescimento das gramíneas. As amostras foram secas a $65^{\circ} \mathrm{C}$ até atingirem massa constante e, posteriormente, moídas em moinho tipo Willey, equipado com peneira fina (40 mesh), e homogeneizadas. Após a digestão nitroperclórica do material vegetal, o fósforo $(\mathrm{P})$ do extrato foi determinado por colorimetria, no comprimento de onda de $725 \mathrm{~nm}$, pelo método da vitamina C (Braga \& De Felipo, 1974). Nesse mesmo extrato, o K foi determinado por fotometria de chama; as análises de $\mathrm{Ca}, \mathrm{Mg}, \mathrm{Fe}, \mathrm{Zn}, \mathrm{Mn}$ e $\mathrm{Cu}$ foram determinadas em espectrofotômetro de absorção atômica, e a de enxofre (S), por turbidimetria do sulfato (Jackson, 1958). Após digestão sulfúrica, foi determinado o teor de N-orgânico, utilizando-se do reagente de Nessler, descrito por Cataldo et al. (1975).

Para interpretação dos dados, empregouse a análise de variância, utilizando-se o teste $\mathrm{F}(\mathrm{P} \leq 0,05)$. Efetuou-se o desdobramento da interação significativa, empregando-se o teste de Tukey a $5 \%$ de probabilidade para as comparações entre espécies e análise de regressão para as densidades de planta daninha, com escolha dos modelos baseada na sua significância, no fenômeno biológico e no coeficiente de determinação ( $\mathrm{R}^{2}=\mathrm{S} . \mathrm{Q}$. Reg./S.Q. Trat.).

\section{RESULTADOS E DISCUSSÃO}

Houve interação significativa entre os fatores espécies de plantas daninhas e densidade para os teores foliares de $\mathrm{N}, \mathrm{K}$ e $\mathrm{S}$ no café. Dessa forma, a interação foi desdobrada, estudando-se as densidades para cada espécie de planta daninha. Quanto aos demais nutrientes, houve efeito significativo somente da densidade de plantas daninhas.

A concentração de $\mathrm{N}$ na folha do café que conviveu com gramíneas apresentou redução linear de 0,59, 0,59 e 0,33 $\mathrm{g} \mathrm{kg}^{-1}$, com aumento da densidade de $B$. decumbens, $D$. horizontalis e B. plantaginea, respectivamente. Todavia, ocorreu acréscimo no teor de $\mathrm{N}$ nas folhas de plantas de café que conviveram com $M$. aterrima, observando-se modelo quadrático até a densidade de 4,17 plantas por vaso, atingindo a concentração máxima de $21,53 \mathrm{~g} \mathrm{~kg}^{-1}$; a partir desse ponto, começou a haver declínio dessa concentração nas folhas de café (Tabela 1 e Figura 1A). Portanto, a contribuição de $M$. aterrima, através da fixação biológica de $\mathrm{N}$, possivelmente é válida até certa densidade, a partir da qual há competição por outros fatores e, consequentemente, queda no teor desses macronutrientes. O N é o nutriente mais exigido quantitativamente pelos cafeeiros jovens. As alterações provocadas nas plantas pela deficiência de nitrogênio manifestam-se nos seguintes sintomas visiveis: redução no crescimento e clorose que se inicia em folhas 
Tabela 1 - Concentrações foliares de macronutrientes em plantas de café em função da densidade de plantas daninhas, após 90 dias de convivência ${ }^{1 /}$

\begin{tabular}{|l|c|c|c|c|c|c|}
\hline \multirow{2}{*}{ Tratamento } & \multicolumn{7}{|c|}{ Variáveis } \\
\cline { 2 - 7 } & $\mathrm{N}$ & $\mathrm{P}$ & $\mathrm{K}$ & $\mathrm{Ca}$ & $\mathrm{Mg}$ & $\mathrm{S}$ \\
\cline { 2 - 7 } & \multicolumn{7}{|c|}{ Densidade 0} \\
\hline B. decumbens & $18,2 \mathrm{a}$ & $1,9 \mathrm{a}$ & $21,0 \mathrm{a}$ & $8,4 \mathrm{a}$ & $8,9 \mathrm{a}$ & $2,1 \mathrm{a}$ \\
\hline D. horizontalis & $19,3 \mathrm{a}$ & $1,9 \mathrm{a}$ & $21,6 \mathrm{a}$ & $8,6 \mathrm{a}$ & $9,2 \mathrm{a}$ & $2,2 \mathrm{a}$ \\
\hline B. plantaginea & $19,6 \mathrm{a}$ & $2,0 \mathrm{a}$ & $21,7 \mathrm{a}$ & $8,72 \mathrm{a}$ & $8,9 \mathrm{a}$ & $2,2 \mathrm{a}$ \\
\hline M. aterrima & $19,1 \mathrm{a}$ & $1,9 \mathrm{a}$ & $21,1 \mathrm{a}$ & $8,6 \mathrm{a}$ & $9,4 \mathrm{a}$ & $2,1 \mathrm{a}$ \\
\hline \multicolumn{7}{|c|}{ Densidade 2} \\
\hline B. decumbens & $17,6 \mathrm{a}$ & $1,5 \mathrm{a}$ & $17,7 \mathrm{a}$ & $7,3 \mathrm{~b}$ & $6,3 \mathrm{~b}$ & $1,8 \mathrm{ab}$ \\
\hline D. horizontalis & $18,3 \mathrm{a}$ & $1,6 \mathrm{a}$ & $19,0 \mathrm{a}$ & $8,4 \mathrm{ab}$ & $8,1 \mathrm{ab}$ & $2,7 \mathrm{a}$ \\
\hline B. plantaginea & $17,9 \mathrm{a}$ & $1,9 \mathrm{a}$ & $16,5 \mathrm{~b}$ & $7,8 \mathrm{ab}$ & $7,8 \mathrm{ab}$ & $1,7 \mathrm{~b}$ \\
\hline M. aterrima & $18,2 \mathrm{a}$ & $1,7 \mathrm{a}$ & $15,6 \mathrm{~b}$ & $9,31 \mathrm{a}$ & $9,3 \mathrm{a}$ & $1,6 \mathrm{~b}$ \\
\hline \multicolumn{7}{|c|}{ Densidade 4} \\
\hline B. decumbens & $16,9 \mathrm{~b}$ & $1,6 \mathrm{a}$ & $18,9 \mathrm{a}$ & $7,1 \mathrm{~b}$ & $6,3 \mathrm{~b}$ & $1,9 \mathrm{a}$ \\
\hline D. horizontalis & $16,3 \mathrm{~b}$ & $1,5 \mathrm{a}$ & $17,6 \mathrm{a}$ & $7,7 \mathrm{ab}$ & $7,2 \mathrm{ab}$ & $1,7 \mathrm{a}$ \\
\hline B. plantaginea & $16,2 \mathrm{~b}$ & $1,6 \mathrm{a}$ & $15,7 \mathrm{~b}$ & $7,5 \mathrm{~b}$ & $7,2 \mathrm{ab}$ & $1,5 \mathrm{a}$ \\
\hline M. aterrima & $21,5 \mathrm{a}$ & $1,6 \mathrm{a}$ & $15,8 \mathrm{~b}$ & $8,9 \mathrm{a}$ & $8,9 \mathrm{a}$ & $1,5 \mathrm{a}$ \\
\hline \multicolumn{7}{|c|}{ Densidade 6} \\
\hline B. decumbens & $16,7 \mathrm{~b}$ & $1,5 \mathrm{a}$ & $16,3 \mathrm{a}$ & $6,8 \mathrm{~b}$ & $6,7 \mathrm{a}$ & $1,6 \mathrm{a}$ \\
\hline D. horizontalis & $16,0 \mathrm{~b}$ & $1,6 \mathrm{a}$ & $16,1 \mathrm{a}$ & $7,5 \mathrm{~b}$ & $7,2 \mathrm{a}$ & $1,7 \mathrm{a}$ \\
\hline B. plantaginea & $16,1 \mathrm{~b}$ & $1,6 \mathrm{a}$ & $15,5 \mathrm{a}$ & $7,4 \mathrm{~b}$ & $6,9 \mathrm{a}$ & $1,5 \mathrm{a}$ \\
\hline M. aterrima & $20,2 \mathrm{a}$ & $1,5 \mathrm{a}$ & $15,7 \mathrm{a}$ & $9,1 \mathrm{a}$ & $8,3 \mathrm{a}$ & $1,9 \mathrm{a}$ \\
\hline ESP*DEN & $*$ & $\mathrm{~ns}$ & $*$ & $\mathrm{~ns}$ & $\mathrm{~ns}$ & $*$ \\
\hline CV\% & 6,8 & 10,1 & 27,3 & 9,6 & 15,9 & 27,2 \\
\hline
\end{tabular}

1/ Para cada densidade, médias seguidas de letras iguais na coluna não diferem entre si pelo teste de Tukey. ESP - espécie; DEN densidade; CV - coeficiente de variação * Significativo a 5\%; e ns - não significativo.

mais velhas - esses sintomas foram observados em muitas plantas que conviveram, principalmente, com as maiores densidades de plantas daninhas.

As folhas de plantas de café livres de competição apresentaram concentração de $\mathrm{P}$ igual a $0,37 \mathrm{~g} \mathrm{~kg}^{-1}(19,5 \%)$, superior à das plantas de café que conviveram com a densidade de seis plantas daninhas por vaso, independentemente da espécie em competição (Tabela 1 e Figura 1B). O fósforo, na fase jovem da cultura, tem importância por aumentar significativamente o sistema radicular das plantas recém-plantadas.

Houve redução direta na concentração de $\mathrm{K}$ nas plantas de café: de 0,72 e 0,98 $\mathrm{g} \mathrm{kg}^{-1}$ para cada planta de $B$. decumbens e $D$. horizontalis que foi adicionada ao vaso. Para $B$. plantaginea e $M$. aterrima, houve menor acúmulo no teor de $\mathrm{K}$, sendo o efeito mais severo observado nas densidade de duas e quatro plantas por vaso; a redução foi explicada pelo modelo exponencial (Figura 1C).

Verificou-se redução nos teores de $\mathrm{Ca}, \mathrm{Mg}$ e $\mathrm{S}$ à medida que se aumentou a densidade de plantas daninhas, independentemente da espécie (Figura 1D, E, F). As concentrações de Ca reduziram $0,15 \mathrm{~g} \mathrm{~kg}^{-1}$ para cada unidade de planta daninha adicionada ao vaso (Figura 1D), independentemente da espécie. Na densidade de seis plantas por vaso, as concentrações de Ca foram de $7,75 \mathrm{~g} \mathrm{~kg}^{-1}$, e nos cafeeiros livres de plantas daninhas elas foram, em média, de 8,57 , para $B$. decumbens, $D$. horizontalis, $B$. plantaginea e $M$. aterrima (Tabela 2). Em processo de competição com espécies de plantas daninhas por período prolongado e em altas densidades, as plantas jovens de café podem apresentar limitação na absorção desses nutrientes, prejudicando seu desenvolvimento e crescimento.

$\mathrm{O}$ teor de $\mathrm{S}$ foi menor nas folhas de plantas de café que conviveram com as plantas daninhas, com redução linear dessa variável com o aumento da população de $D$. horizontalis; para as demais espécies, a redução segue modelo exponencial de redução (Figura 1D). O teor de $\mathrm{S}$ nas plantas de café foi de 1,$6 ; 1,7 ; 1,5$; e $1,9 \mathrm{~g} \mathrm{~kg}^{-1}$, na densidade de seis plantas por vaso, para $B$. decumbens, $D$. horizontalis, $B$. plantaginea e $M$. aterrima, respectivamente. Todavia, as plantas de café que se desenvolveram sem a interferência dessas plantas daninhas apresentaram concentração média de $2,15 \mathrm{~g} \mathrm{~kg}^{-1}$ (Tabela 1 ).

Independentemente da espécie de planta daninha que conviveu com plantas de café, observou-se menor acúmulo do teor de $\mathrm{Mg}$ nas folhas da cultura com o aumento da densidade de plantas daninhas (Figura 1E).

Com relação aos micronutrientes, os teores de $\mathrm{Cu}$ e $\mathrm{Mn}$ reduziram exponencialmente, de forma expressiva, até duas plantas daninhas por vaso; a partir dessa densidade, $\mathrm{O}$ teor foi mantido nas folhas no café (Figura 2A, $\mathrm{B})$. Os teores de $\mathrm{Fe}$ e $\mathrm{Zn}$ reduziram linearmente com o aumento da densidade de plantas daninhas, independentemente da espécie (Figura 2C, D). O teor foliar de Cu reduziu em aproximadamente $50 \%$, passando de $6,0 \mathrm{mg} \mathrm{kg}^{-1}$ 

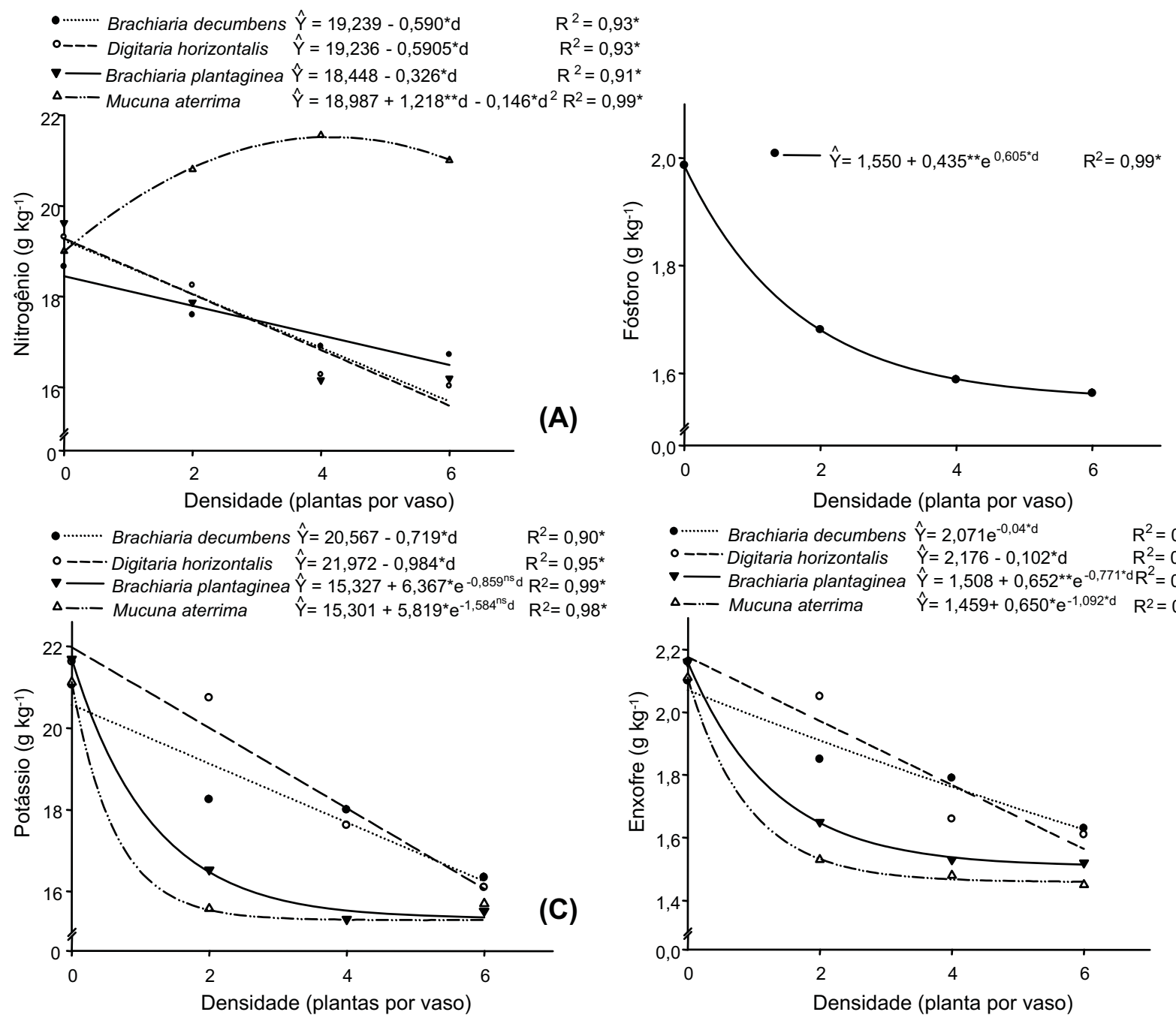

(B)
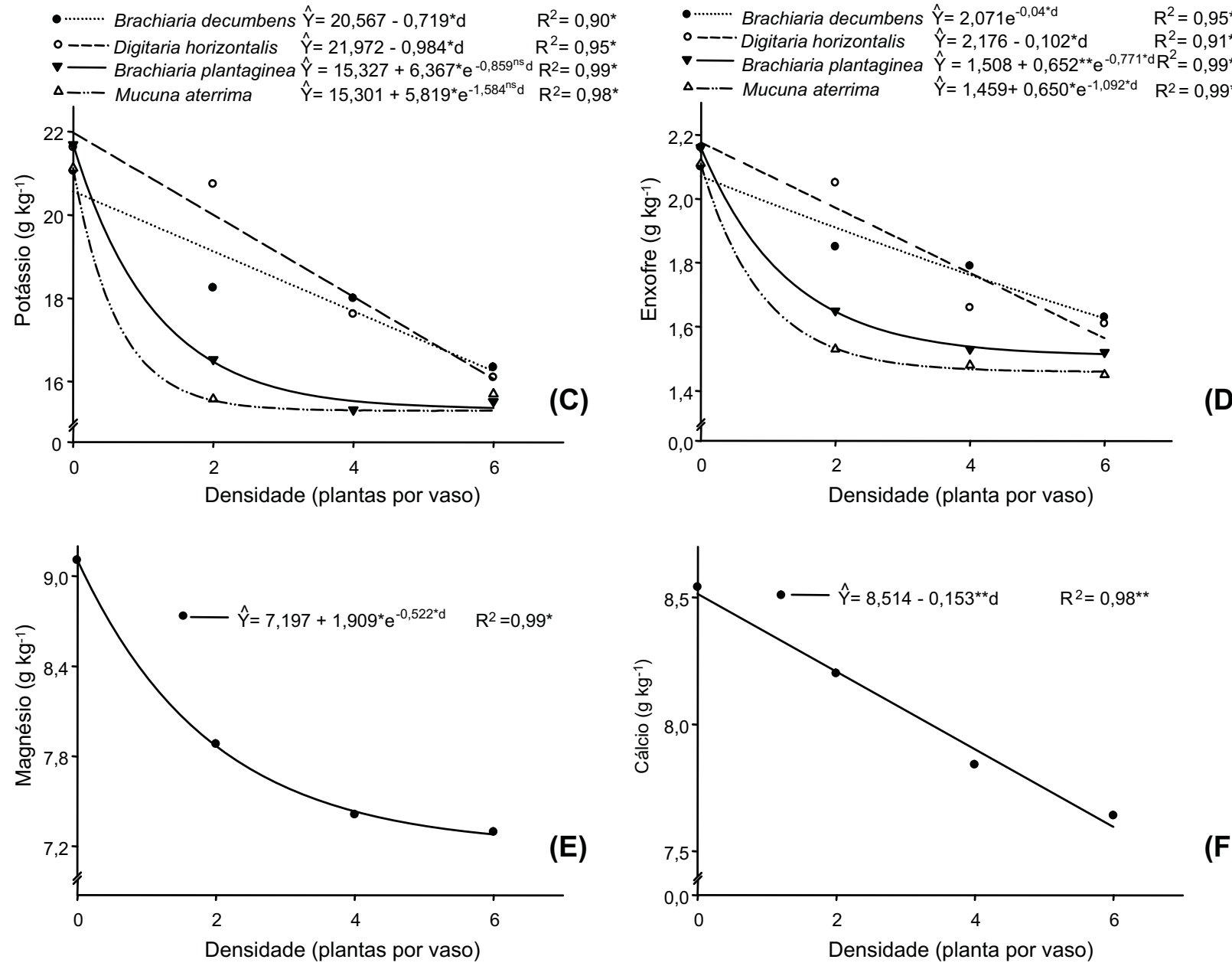

(F)

(*,** Teste $\mathrm{F} ; \mathrm{P}<0,05$ e $\mathrm{P}<0,01$, respectivamente).

Figura 1 - Teores de nitrogênio (A), fósforo (B), potássio (C), enxofre (D), magnésio (E) e cálcio (E) em folhas de plantas de café em função da densidade de plantas daninhas, após 90 dias de convivência no vaso. 
Tabela 2 - Concentrações foliares de macronutrientes de plantas daninhas em diferentes densidades, após 90 dias de convivência com plantas de café ${ }^{\prime}$

\begin{tabular}{|l|c|c|c|c|c|c|}
\hline \multirow{2}{*}{ Espécie } & \multicolumn{7}{|c|}{ Variáveis } \\
\cline { 2 - 7 } & $\mathrm{N}$ & $\mathrm{P}$ & $\mathrm{K}$ & $\mathrm{Ca}$ & $\mathrm{Mg}$ & $\mathrm{S}$ \\
\cline { 2 - 7 } & \multicolumn{7}{|c|}{ Densidade 2} \\
\hline B. decumbens & $11,2 \mathrm{~b}$ & $3,5 \mathrm{~b}$ & $7,3 \mathrm{a}$ & $5,8 \mathrm{c}$ & $6,5 \mathrm{~b}$ & $1,9 \mathrm{~b}$ \\
\hline D. horizontalis & $9,9 \mathrm{~b}$ & $8,3 \mathrm{a}$ & $7,0 \mathrm{ab}$ & $8,6 \mathrm{~b}$ & $7,5 \mathrm{~b}$ & $2,3 \mathrm{a}$ \\
\hline B. plantaginea & $9,2 \mathrm{~b}$ & $11,0 \mathrm{a}$ & $5,1 \mathrm{~b}$ & $7,3 \mathrm{bc}$ & $10,5 \mathrm{a}$ & $2,1 \mathrm{ab}$ \\
\hline M. aterrima & $24,9 \mathrm{a}$ & $2,1 \mathrm{c}$ & $5,8 \mathrm{ab}$ & $11,2 \mathrm{a}$ & $1,2 \mathrm{c}$ & $2,4 \mathrm{a}$ \\
\hline & \multicolumn{7}{|c|}{ Densidade 4} \\
\hline B. decumbens & $10,9 \mathrm{~b}$ & $4,0 \mathrm{~b}$ & $7,1 \mathrm{a}$ & $5,6 \mathrm{c}$ & $6,0 \mathrm{~b}$ & $1,7 \mathrm{~b}$ \\
\hline D. horizontalis & $10,0 \mathrm{~b}$ & $8,6 \mathrm{a}$ & $6,9 \mathrm{a}$ & $8,5 \mathrm{~b}$ & $4,3 \mathrm{c}$ & $2,2 \mathrm{a}$ \\
\hline B. plantaginea & $9,0 \mathrm{~b}$ & $9,7 \mathrm{a}$ & $5,2 \mathrm{a}$ & $7,3 \mathrm{bc}$ & $10,1 \mathrm{a}$ & $2,2 \mathrm{a}$ \\
\hline M. aterrima & $27,1 \mathrm{a}$ & $1,9 \mathrm{c}$ & $5,7 \mathrm{a}$ & $11,0 \mathrm{a}$ & $1,1 \mathrm{~d}$ & $2,3 \mathrm{a}$ \\
\hline & \multicolumn{7}{|c|}{ Densidade 6} \\
\hline B. decumbens & $11,7 \mathrm{~b}$ & $2,9 \mathrm{~b}$ & $5,6 \mathrm{a}$ & $5,2 \mathrm{c}$ & $5,4 \mathrm{~b}$ & $1,7 \mathrm{~b}$ \\
\hline D. horizontalis & $9,9 \mathrm{~b}$ & $9,6 \mathrm{a}$ & $6,8 \mathrm{a}$ & $7,7 \mathrm{ab}$ & $4,4 \mathrm{~b}$ & $2,2 \mathrm{a}$ \\
\hline B. plantaginea & $10,1 \mathrm{~b}$ & $9,5 \mathrm{a}$ & $5,1 \mathrm{a}$ & $6,5 \mathrm{bc}$ & $9,6 \mathrm{a}$ & $2,2 \mathrm{a}$ \\
\hline M. aterrima & $28,1 \mathrm{a}$ & $1,9 \mathrm{~b}$ & $5,7 \mathrm{a}$ & $8,8 \mathrm{a}$ & $1,1 \mathrm{c}$ & $2,3 \mathrm{a}$ \\
\hline DEN*ESP & $\mathrm{ns}$ & $* *$ & $\mathrm{~ns}$ & $\mathrm{~ns}$ & $* *$ & $\mathrm{~ns}$ \\
\hline CV (\%) & 16,3 & 13,2 & 16,3 & 12,6 & 11,6 & 8,5 \\
\hline
\end{tabular}

1/ Para cada densidade, médias seguidas de letras iguais na coluna não diferem entre si pelo teste de Tukey $(\mathrm{P}<0,05)$. ${ }^{*}$ Significativo a 5\%; e ns - não significativo.

em plantas que se desenvolveram na ausência das plantas daninhas para $3,0 \mathrm{mg} \mathrm{kg}^{-1}$ nas plantas de café que se desenvolveram na presença de seis plantas daninhas por vaso (Figura 2A). Ronchi et al. (2003) verificaram, em média, 13,88 vezes mais micronutrientes em Richardia brasiliensis,em relação ao teor encontrado no café.

Quanto aos teores de Fe e $\mathrm{Zn}$, houve redução direta à medida que se aumentou o número de plantas daninhas por vaso, com redução de 2,95 e $0,17 \mathrm{mg} \mathrm{kg}^{-1}$, respectivamente, no teor desses micronutrientes nas folhas do cafeeiro. As plantas que se desenvolveram livres da interferência de plantas daninhas apresentaram 17,0 $\mathrm{mg} \mathrm{kg}^{-1}$ mais teor de Fe que as plantas de café que se desenvolveram juntamente com seis plantas daninhas por vaso (Figura 2C, D).

Os procedimentos diretos para avaliação do estado nutricional das plantas são aqueles em que as concentrações são aparentes (sintomas visuais) e/ou reais (análise dos teores de nutrientes na matéria seca). Como a folha é o principal órgão responsável pela produção vegetal, graças à fotossintese, os seus teores de nutrientes apresentam melhor correlação com o rendimento - razão de a análise preferencial ser a foliar.

Durante o período de execução do experimento e, principalmente, no fim dos 90 dias de convívio no vaso, observaram-se, nas plantas de café, vários sintomas de deficiência nutricional. Os principais foram: coloração verde-escura das nervuras e folhas distorcidas e desuniformes e de coloração avermelhada. Além disso, verificou-se redução de sistema radicular e redução no desenvolvimento da parte aérea das plantas jovens de café em convivência com plantas daninhas (Fialho et al., 2011).

Antes da manifestação visivel da deficiência, o crescimento e a produção já poderão estar comprometidos. Os sintomas visiveis são o fim de uma série de eventos que têm início com alterações em âmbito molecular (Malavolta, 2006). Assim, essas mudas, em campo, já estariam comprometidas, afetando posteriormente a produção e qualidade da lavoura.

Houve interação significativa entre os fatores espécies de plantas daninhas e densidade de plantio para os teores foliares de P, $\mathrm{Mg}$ e Mn. Dessa forma, a interação foi desdobrada, estudando-se as densidades para cada espécie de planta daninha. Quanto aos demais nutrientes, o efeito significativo ocorreu somente entre as espécies de plantas daninhas avaliadas (Tabelas 2 e 3 ).

M. aterrima apresentou os maiores teores de $\mathrm{N}$ em relação às outras espécies de plantas daninhas, em todos os níveis de competição, com teores foliares atingindo $28,1 \mathrm{~g} \mathrm{~kg}^{-1}$ na densidade de seis plantas. Nas gramineas, nessa mesma densidade, os teores foram de $11,7,9,9$ e $10,1 \mathrm{~g} \mathrm{~kg}^{-1}$ para $B$. decumbens, $D$. horizontalis e $B$. plantaginea, respectivamente (Tabela 2). Esse maior teor de $\mathrm{N}$ em $M$. aterrima deve-se ao fato de suas raízes desenvolverem associações com bactérias fixadoras de $\mathrm{N}$, o que lhe permite capturar o $\mathrm{N}$ do ar com seus nódulos (Evans \& Edwards, 2001). 

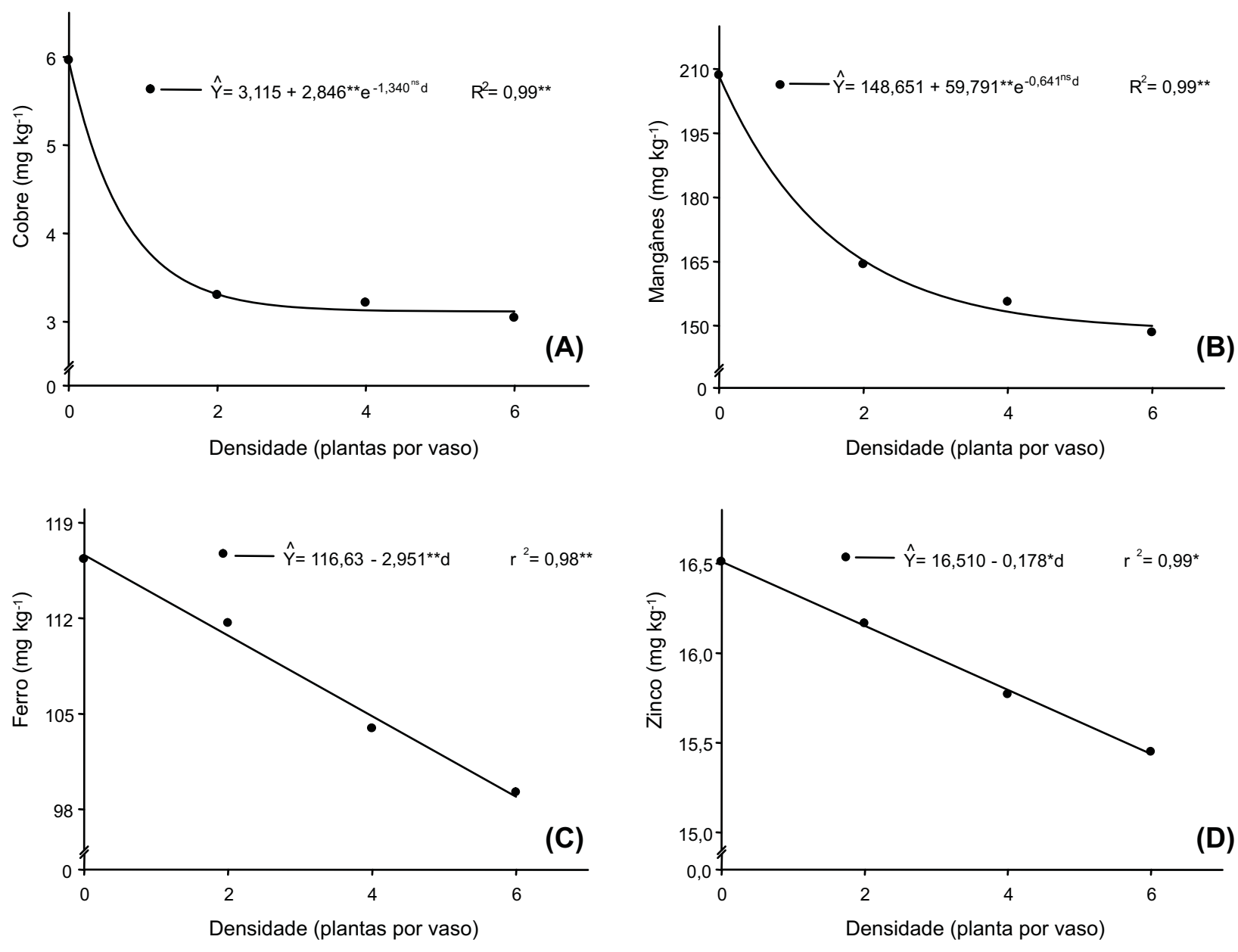

$(*, * *$ Teste $\mathrm{F} ; \mathrm{P}<0,05$ e $\mathrm{P}<0,01$, respectivamente).

Figura 2 - Teores de cobre (A), manganês (B), ferro (C) e zinco (D) em folhas de plantas de café em função da densidade de plantas daninhas, após 90 dias de convivência no vaso.

$\mathrm{O}$ teor de $\mathrm{P}$ apresentou modelo exponencial de redução para $B$. plantaginea, com teor de 11 , 9,7 e 9,5 $\mathrm{g} \mathrm{kg}^{-1}$ para as densidades de duas, quatro e seis plantas daninhas, respectivamente (Tabelas 2 e 3). Para B. decumbens, $D$. horizontalis e $M$. aterrima, não houve efeito significativo do teor de $\mathrm{P}$ com o aumento de plantas daninhas por vaso, com os seguintes valores médios: 3,48, 8,81 e 1,97 $\mathrm{g} \mathrm{kg}^{-1}$, respectivamente. Para a densidade de duas e quatro plantas daninhas por vaso, B. plantaginea e $D$. horizontalis foram as espécies com os maiores teores de $\mathrm{P}$, sendo, na densidade de duas plantas por vaso, de 11 e $8,3 \mathrm{~g} \mathrm{~kg}^{-1}$, respectivamente. Para a densidade de seis plantas daninhas por vaso, os menores valores foram observados para $M$. aterrima e $B$. decumbens: 1,9 e 2,9 $\mathrm{g} \mathrm{kg}^{-1}$, respectivamente (Tabela 2).

$\mathrm{O}$ teor de $\mathrm{K}$ nas plantas daninhas não diferiu entre as densidades de quatro e seis plantas por vaso, havendo diferença somente na densidade de duas plantas daninhas por vaso; $B$. plantaginea apresentou o menor valor: $5,1 \mathrm{~kg}^{-1}$ (Tabela 2).

Mucuna aterrima foi a espécie com maior teor de $\mathrm{Ca}$ para todas as densidades, com valores de $11,2 \mathrm{~g} \mathrm{~kg}^{-1}$ na densidade de duas plantas por vaso. Nessa mesma densidade, $B$. decumbens, $D$. horizontalis e $B$. plantaginea apresentaram os seguintes teores: 5,8, 8,6 e $7,3 \mathrm{~g} \mathrm{~kg}^{-1}$, respectivamente (Tabela 2). 
Tabela 3 - Equações referentes aos teores de nutrientes em folhas de plantas daninhas (Y) em diferentes densidades (d), após 90 dias de convivência com uma planta de café

\begin{tabular}{|c|c|c|c|}
\hline Espécie & Variável & Equações ajustadas & $\mathrm{R}^{2}$ \\
\hline B. decumbens & \multirow{4}{*}{$\mathrm{P}\left(\mathrm{g} \mathrm{kg}^{-1}\right)$} & $\hat{\mathrm{Y}}=\mathrm{Y}=3,48$ & -- \\
\hline D. horizontalis & & $\hat{\mathrm{Y}}=\mathrm{Y}=8,81$ & -- \\
\hline B. plantaginea & & $\hat{\mathrm{Y}}=11,78 \mathrm{e}^{(-0,0036 \mathrm{~d})}$ & $0,96^{*}$ \\
\hline M. aterrima & & $\hat{\mathrm{Y}}=\mathrm{Y}=1,97$ & -- \\
\hline B. decumbens & \multirow{4}{*}{$\operatorname{Mg}\left(\mathrm{g} \mathrm{kg}^{-1}\right)$} & $\hat{\mathrm{Y}}=\mathrm{Y}=5,95$ & -- \\
\hline D. horizontalis & & $\hat{\mathrm{Y}}=9,016-0,72 \mathrm{~d}$ & $0,98^{*}$ \\
\hline B. plantaginea & & $\hat{\mathrm{Y}}=\mathrm{Y}=10,08$ & -- \\
\hline M. aterrima & & $\hat{\mathrm{Y}}=\mathrm{Y}=1,22$ & -- \\
\hline B. decumbens & \multirow{4}{*}{$\operatorname{Mn}\left(\mathrm{mg} \mathrm{kg}^{-1}\right)$} & $\hat{\mathrm{Y}}=\mathrm{Y}=170,44$ & -- \\
\hline D. horizontalis & & $\hat{\mathrm{Y}}=\mathrm{Y}=259,83$ & -- \\
\hline B. plantaginea & & $\hat{\mathrm{Y}}=147,30+11,12 \mathrm{~d}$ & $0,85^{*}$ \\
\hline M. aterrima & & $\hat{\mathrm{Y}}=196-10,15 \mathrm{~d}$ & $0,92 *$ \\
\hline
\end{tabular}

O teor foliar de $\mathrm{Mg}$ nas plantas de $D$. horizontalis apresentou comportamento linear, com redução de $0,72 \mathrm{~g} \mathrm{~kg}^{-1}$ a cada planta daninha que foi adicionada ao vaso. Para as demais espécies, não houve efeito significativo da densidade de plantas daninhas, com valores médios de 5,95, 10,08 e $1,22 \mathrm{~g} \mathrm{~kg}^{-1}$ para $B$. decumbens, $B$. plantaginea e $M$. aterrima (Tabela 3). Independentemente da densidade, a espécie com maior teor de $\mathrm{Mg}$ foi $B$. plantaginea, e a com menor valor foi $M$. aterrima, com valores até 10 vezes menores que os de $B$. plantaginea (Tabela 2).

Entre os micronutrientes, o teor de $\mathrm{Cu}$ nas plantas daninhas não apresentou diferença quanto à espécie utilizada em todas as densidades. O teor foliar de Fe foi maior nas espécies de $D$. horizontalis, com valor de $134,3 \mathrm{~g} \mathrm{~kg}^{-1}$ na densidade de seis plantas daninhas (Tabela 4).

$\mathrm{O}$ teor foliar de $\mathrm{Mn}$ em B. plantaginea apresentou aumento linear de $11,12 \mathrm{mg} \mathrm{kg}^{-1}$ para cada planta daninha adicionada ao vaso, e $M$. aterrima apresentou modelo linear de redução de $10,15 \mathrm{mg} \mathrm{kg}^{-1}$, para cada planta daninha adicionada ao vaso. $B$. decumbens e $D$. horizontalis não apresentaram efeito significativo com o aumento da densidade, com valores médios de 170,44 e 259,83, respectivamente (Tabela 4). $M$. aterrima e B. plantaginea foram as espécies que mostraram os maiores teores foliares de $\mathrm{Zn}$ em todas as densidades (Tabela 4).

No caso do cafeeiro, por ser cultura perene, os erros cometidos no início do cultivo podem comprometer a produtividade por toda a vida da cultura, especialmente quanto à nutrição de mudas e plantas em formação em campo (Clemente et al., 2008). Mal nutrido, tem seu crescimento e potencial competitivo com a planta daninha cada vez menores, tornandose, inclusive, mais sensivel ao ataque de patógenos, pois acredita-se que a tolerância de uma cultura a pragas e doenças e a herbicidas seja também influenciada pelo seu estado nutricional (Ronchi et al., 2003).

Apesar dos beneficios da fixação biológica de $\mathrm{N}$, reciclagem de nutrientes e cobertura do solo por M. aterrima (Perin et al., 2004), há redução no teor de nutrientes na planta de café quando se desenvolve na linha da cultura, inclusive de $\mathrm{N}$, quando se apresenta em altas densidades.

De modo geral, concentrações de macro e micronutrientes nas plantas jovens de café foram influenciadas pela presença de plantas daninhas que conviveram em mesmo ambiente, com tendência de menores teores de

Tabela 4 - Concentrações de micronutrientes foliares de plantas daninhas em diferentes densidades, após 90 dias de convivência com plantas de café ${ }^{1 /}$

\begin{tabular}{|c|c|c|c|c|}
\hline \multirow{3}{*}{ Espécie } & \multicolumn{4}{|c|}{ Variáveis } \\
\hline & $\mathrm{Cu}$ & $\mathrm{Fe}$ & $\mathrm{Mn}$ & $\mathrm{Zn}$ \\
\hline & \multicolumn{4}{|c|}{$\left(\mathrm{g} \mathrm{kg}^{-1}\right)$} \\
\hline \multicolumn{5}{|c|}{ Densidade 2} \\
\hline B. decumbens & $5,9 \mathrm{a}$ & $108,2 \mathrm{ab}$ & $185,8 \mathrm{~b}$ & $23,1 \mathrm{~b}$ \\
\hline D. horizontalis & $5,6 \mathrm{a}$ & $126,2 \mathrm{a}$ & $174,8 \mathrm{~b}$ & $22,1 \mathrm{~b}$ \\
\hline B. plantaginea & $6,5 \mathrm{a}$ & $104,7 \mathrm{~b}$ & $270,4 \mathrm{a}$ & $32,8 \mathrm{a}$ \\
\hline M. aterrima & $7,4 \mathrm{a}$ & $99,87 \mathrm{~b}$ & $178,9 \mathrm{~b}$ & $31,3 \mathrm{a}$ \\
\hline \multicolumn{5}{|c|}{ Densidade 4} \\
\hline B. decumbens & $5,0 \mathrm{a}$ & $100,1 \mathrm{~b}$ & $170,5 \mathrm{~b}$ & $20,6 \mathrm{~b}$ \\
\hline D. horizontalis & $4,9 \mathrm{a}$ & $124,1 \mathrm{a}$ & $181,22 \mathrm{~b}$ & $20,2 \mathrm{~b}$ \\
\hline B. plantaginea & $6,9 \mathrm{a}$ & $109,1 \mathrm{ab}$ & $268,62 \mathrm{a}$ & $34,5 \mathrm{a}$ \\
\hline M. aterrima & $6,3 \mathrm{a}$ & $93,7 \mathrm{~b}$ & $118,9 \mathrm{c}$ & $28,6 \mathrm{a}$ \\
\hline \multicolumn{5}{|c|}{ Densidade 6} \\
\hline B. decumbens & $5,7 \mathrm{a}$ & $94,3 \mathrm{c}$ & $155,37 \mathrm{~b}$ & $21,8 \mathrm{~b}$ \\
\hline D. horizontalis & $5,6 \mathrm{a}$ & $134,3 \mathrm{a}$ & $239,3 \mathrm{a}$ & $20,9 \mathrm{~b}$ \\
\hline B. plantaginea & $5,4 \mathrm{a}$ & $115,6 \mathrm{ab}$ & $240,5 \mathrm{a}$ & $31,5 \mathrm{a}$ \\
\hline M. aterrima & $7,9 \mathrm{a}$ & $100,4 b c$ & $138,4 \mathrm{~b}$ & $31,0 \mathrm{a}$ \\
\hline $\mathrm{DEN} * \mathrm{ESP}$ & $\mathrm{ns}$ & $\mathrm{ns}$ & $*$ & $\mathrm{~ns}$ \\
\hline $\mathrm{CV}(\%)$ & 18,3 & 9,7 & 12,4 & 13,6 \\
\hline
\end{tabular}

1/ Para cada densidade, médias seguidas de letras iguais na coluna não diferem entre si pelo teste de Tukey $(\mathrm{P}<0,05) .{ }^{*}$ Significativo a 5\%; e ns - não significativo. 
nutrientes nas folhas da cultura com o aumento da densidade de plantas daninhas. As espécies daninhas destacaram-se com maior teor foliar de alguns nutrientes, sendo $D$. horizontalis em $\mathrm{P}$ e Fe, B. plantaginea em $\mathrm{P}, \mathrm{Mg}, \mathrm{Mn}$ e $\mathrm{Zn}$ e $M$. aterrima em N, Ca e Zn, independentemente da densidade de infestação. Essas espécies, mesmo em baixas densidades, acarretaram menores teores de nutrientes das plantas jovens de café.

\section{LITERATURA CITADA}

ALFONSI, E. L. et. al. Crescimento, fotossíntese e composição mineral em genótipos de Coffea com potencial para utilização como porta-enxerto. Bragantia, v. 64, n. 1, p. 1-13, 2005.

BAUMANN, D. T. et al. Competition and crop performance in a leek-celery intercropping system. Crop Sci., v. 41, n. 3, p. 764-774, 2001.

BRAGA, J. M.; De FELLIPO, B. V. Determinação espectrofotométrica de $\mathrm{P}$ em extratos de solo e material vegetal. R. Ceres, v. 21, n. 113, p. 73-85, 1974.

CATALDO, D. A. et.al. Rapid colorimetric determination of nitrate in plant tissue by nitration of salicylic acid. Comm. Soil Sci. Plan., v. 6, n. 1, p. 71-80, 1975.

CLEMENTE, F. M. V. T, et. al. Faixas criticas de teores foliares de macronutrientes no cafeeiro em pós-plantio primeiro ano. Coffee Sci.. v. 3, n. 1, p. 47-57, 2008.

DI TOMASO, J. M. Approaches for improving crop competitiveness through the manipulation of fertilization strategies. Weed Sci., v. 43, n. 3, p. 491-497, 1995.

EVANS, J. R.; EDWARDS, E. Nutrient uptake and use in plant growth. In: NET ECOSYSTEM EXCHANGE CRC WORKSHOP, 2001, Canberra. Proceedings... Canberra: Cooperative Research Centre for Greenhouse Accounting, 2001. p. 75-81.
FIALHO, C. M. T. et al. Interferência de plantas daninhas sobre o crescimento inicial de Coffea arabica.

Planta Daninha, v. 29, n. 1, p. 137-148, 2011.

JACKSON, M. L. Soil chemical analysis. New Jersey: Prentice Hall, 1958. 498 p.

MALAVOLTA, E. Manual de nutrição de plantas. São Paulo. Agronômica Ceres. 2006. 683 p.

MORTENSEN, D.A.; BASTIAANS, L.; SATTIN, M. The role of ecology in the development of weed management systems: an outlook. Weed Res., v. 40, n. 1, p. 49-62, 2000.

PAULO, E. M. et. al. Produtividade do café apoatã em consórcio com leguminosas na região da Alta Paulista. Bragantia, v. 60, n. 3, p. 195-199, 2001.

PERIN, A. et. al. Produção de fitomassa, acúmulo de nutrientes e fixação biológica de nitrogênio por adubos verdes em cultivo isolado e consorciado. Pesq. Agropec. Bras., v. 39, n. 1, p. 35-40, 2004.

PITELLI, R. A. Interferência de plantas daninhas em culturas agrícolas. Inf. Agropec., v. 120, n. 11, p. 16-27, 1985.

RONCHI, C. P. et al. Acúmulo de nutrientes pelo cafeeiro sob interferência de plantas daninhas. Planta Daninha, v. 21, n. 2, p. 219-227, 2003.

RONCHI, C. P., TERRA A. A., SILVA, A. A. Growth and nutrient concentration in coffee root system under weed species competition. Planta Daninha, v. 25, n. 4, p. 679-687, 2007.

SILVA, A. A. et al. Manejo integrado de plantas daninhas em lavouras de café. In: TOMAZ, M. A. et al. (Eds.). Seminário para a sustentabilidade da cafeicultura. Alegre: UFES, 2008. p. 251-268.

SOUZA, L. S. et al. Efeitos das faixas de controle do capimbraquiária (Brachiaria decumbens) no desenvolvimento inicial e na produtividade do cafeeiro (Coffea arabica). Planta Daninha, v. 24, n. 4, p. 715-720, 2006. 